\title{
Schedule-induced polydipsia as a function of the interval between food pellets
}

\author{
NIGEL BOND \\ Department of Psychology, University of Nottingham, Nottingham NG7 2RD, England
}

\begin{abstract}
Previous attempts to investigate the function-relating degree of polydipsia to interval duration have held constant either session length or the number of intervals per session. In the present study both were held constant by exposing rats to progressive-time and retrogressive-time schedules. In the former, the intervals between pellet deliveries became progressively longer during the session; in the latter, they became progressively shorter. Under both schedules, a bitonic relationship was observed between the total number of licks and the interval between food pellets.
\end{abstract}

If food-deprived rats receive food pellets on an intermittent schedule of reinforcement, they will engage in a bout of drinking shortly after each pellet delivery. This phenomenon was first demonstrated by Falk (1961), and he termed it "schedule-induced polydipsia."

The length of time between pellet deliveries appears to be of prime importance in determining the degree of polydipsia. For example, Falk (1966) systematically explored the degree of schedule-induced drinking as a function of the fixed-interval between food pellets. As the fixed-interval value was increased from $2 \mathrm{sec}$ through values up to $300 \mathrm{sec}$, the amount of water drunk increased linearly up to a maximum point, but fell off at $300 \mathrm{sec}$ to a scarcely polydipsic value. A number of subsequent studies have replicated these findings (Flory, 1971; Hawkins, Schrot, Githens, \& Everett, 1972; Keehn \& Colotla, 1971).

All the above experiments held the number of food pellets delivered per session constant; thus as the interpellet interval increased, session duration increased. Hawkins et al. (1972) held session length constant while exposing rats to a number of different fixed-interval schedules. They found that as the duration of the fixed-interval increased, total session fluid intake declined monotonically. Because session duration was held constant, as the fixed-interval duration increased, so the number of intervals per session decreased. Only by employing a measure of relative intake, e.g., milliliters per interval, were the resultant changes in fluid intake represented by a bitonic curve. It would appear that an experiment which held constant both session length and the number of intervals, would be useful. The present

This work was carried out under a Science Research studentship. Thanks are due to Dr. D. E. Blackman for his support and suggestions throughout the course of the study. Reprints may be obtained from the author, School of Behavioural Sciences, Macquarie University, North Ryde, N. S. W., Australia, 2113. Dr. C. T. Morgan sponsors this paper and takes full editorial responsibility for its content. experiment sought to control for these variables by employing progressive-time (PT) and retrogressivetime (RT) schedules. In such schedules, interval duration changes throughout the course of the session, either increasing monotonically (P'T), or decreasing monotonically (RT). It would be difficult to measure the water intake during each interval of such a schedule. Therefore, the number of licks was employed as an approximation. Since this measure was taken from each individual animal and from within the same session, it is reasonable to assume that it provided a close estimate of an animals' relative water intake during the various intervals presented.

\section{METHOD}

\section{Subjects}

Two naive male hooded Lister rats were used. They were housed individually and maintained at $80 \%$ of their free-feeding weights, which were approximately $290 \mathrm{~g}$. Water was always available in their home cages.

\section{Apparatus}

Two Grason-Stadler E3125B rat stations mounted inside sound-attenuating chests. A foodtray was mounted in the center of one wall, just above the grid floor. Food could be dispensed into this tray in the form of 45-mg pellets (P. J. Noyes, Standard Formula). Directly above the foodtray was a green jeweled stimulus lamp which provided illumination during the experimental sessions. An aperture to the right of the tray allowed access to the metal nozzle of a water bottle. The experiment was fully automated, and the results were recorded on a printout counter and a cumulative recorder.

\section{Procedure}

Daily experimental sessions were $150 \mathrm{~min}$ in length, during which time 61 food pellets were delivered. No preliminary training was necessary as pellet delivery was completely independent of behavior.

The experiment began with the progressive-time (PT) schedule in operation, i.e., the intervals between pellet delivery became progressively longer as each session proceeded. The 60 intervals in each daily session ranged from $5 \mathrm{sec}$ to $300 \mathrm{sec}$ in length, each interval being longer than the one immediately preceding it by 5 -sec. Phase 1 was in operation for 30 sessions before Phase 2 was introduced.

In Phase 2, the animals were transferred to a fixed-time (FT) 
schedule in which the interpellet interval was held constant at $150 \mathrm{sec}$, i.e., the arithmetic mean of all the intervals in the progressive-time (PT) schedule.

After 15 sessions exposure to Phase 2, Phase 3 was introduced. In this phase, the retrogressive-time schedule was in operation, i.e., the intervals between pellet delivery became progressively shorter as the session proceeded. The interval values were the same as those used in Phase 1, but in this phase, sessions began with the longest interval and ended with the shortest. This phase was in operation for 30 sessions.

\section{RESULTS}

The data for Phases 1 and 3 were taken from the last session that these phases were in operation. For clarity and ease of comparison, the points in Figure 1 are the sum of 12 consecutive interpellet intervals. Thus the first point is the sum of the interpellet intervals whose durations range from $5 \mathrm{sec}$ to $60 \mathrm{sec}$, the second point is the sum of the intervals whose durations range from $65 \mathrm{sec}$ to $120 \mathrm{sec}$, and so on.

Figure 1A shows the functions relating the total number of licks and the interval duration under the progressive-time (PT) schedule (Phase 1). Both subjects exhibited a bitonic relationship with a maximum at the point which is the sum of the intervals whose durations range from $65 \mathrm{sec}$ to $120 \mathrm{sec}$.

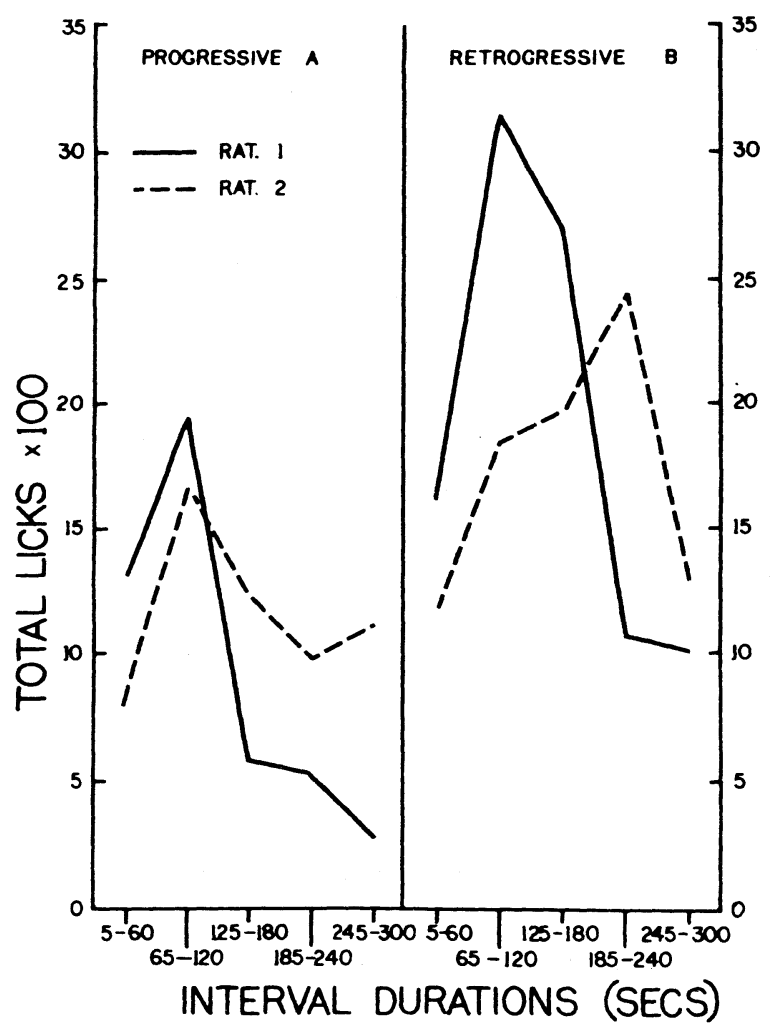

Figure 1. Total number of licks as a function of the interval duration. A: Progressive-time schedule. B. Retrogressive-time schedule.
Table 1

Total Number of Licks and Amount of Water Displaced from the Drinking Bottle for the Last Session of Each Phase of the Experiment

\begin{tabular}{ccccc} 
& \multicolumn{2}{c}{ Rat 1} & \multicolumn{2}{c}{ Rat 2 } \\
Phase & Licks & Ml & Licks & Ml \\
\hline 1 & 4640 & 18 & 5816 & 28 \\
2 & 4548 & 20 & 2851 & 18 \\
3 & 8765 & 37 & 8424 & 32 \\
\hline
\end{tabular}

Figure 1B shows the functions relating the total number of licks and the interval duration for Phase 3 when the retrogressive-time (RT) schedule was in operation. Both subjects exhibited a bitonic relationship. In Rat 1, the maximum was at the point which is the sum of all the intervals whose durations range from $65 \mathrm{sec}$ to $120 \mathrm{sec}$; in Rat 2 , it was at the point which is the sum of all the intervals whose durations range from $185 \mathrm{sec}$ to $240 \mathrm{sec}$.

It appears from Figure 1 that both subjects made more licks per session during Phase 3 , when the retrogressive-time (RT) schedule was in operation, than in Phase 1, when the progressive-time (PT) schedule was in operation. This is corroborated by Table 1, which shows the total number of licks and the amount of water displaced from the water bottle for the last session of each phase, for both subjects. It is interesting to note that the relationships described in Figure 1 were similar despite this disparity between the two schedules in the total number of licks.

\section{DISCUSSION}

The data reported in the present experiment were concerned with the patterns of schedule-induced licking that developed when rats were exposed to progressive-time (PT) and retrogressive-time (RT) schedules of food pellet delivery. Under the progressive-time (PT) schedule (Phase 1), interpellet intervals became progressively longer as the session proceeded. Under the retrogressive-time (RT) schedule, interpellet intervals became progressively shorter as the session proceeded. In both subjects, under both schedules, the functions relating the total number of licks and the interval duration were represented by an inverted U-shaped curve. For Rat 1, the highest total number of licks was at $65-120 \mathrm{sec}$ under both schedules. For Rat 2, it was at $65-120 \mathrm{sec}$ under the progressive-time (PT) schedule and at $185-240 \mathrm{sec}$ under the retrogressive-time (RT) schedule.

If one accepts the assumption that a measure of licking behavior, taken from the same animal and within the same session, is a good approximation to the animals' relative water intake during that session, then the results described above agree with those reported previously in indicating that the function relating the interpellet interval and water intake is an inverted U-shaped curve (Falk, 1966; Flory, 1971; Hawkins et al., 1972; Keehn \& Colotla, 1971). In previous studies, either the session length or the number of intervals per session varied as the interval between pellets varied. By presenting all the intervals to be studied in the same session, these possible sources of confounding variation were excluded. The fact that the same function was obtained whether the interpellet intervals increased (Phase 1) or decreased (Phase 3) during the session testifies to its replicability. 


\section{POLYDIPSIA AND INTERVAL DURACTION 141}

\section{REFERENCES}

FaLK, J. L. Production of polydipsia in normal rats by an intermittent food schedule. Science, 1961, 133, 195-196.

FalK, J. L. Schedule induced polydipsia as a function of fixed-interval length. Journal of the Experimental Analysis of Behavior, 1966, 9, 37-39.

FLoRY, R. K. The control of schedule induced polydipsia: Frequency and magnitude of reinforcement. Learning and Motivation, 1971, 2, 215-227.

Hawkins, T. D., Schrot, J. F., Githins, S. H., \& Everett, P. B. Schedule-induced polydipsia: An analysis of water and alcohol ingestion. In R. M. Gilbert \& J. D. Keehn (Eds.), Schedule effects: Drugs, drinking and aggression. Toronto: University of Toronto Press, 1972. Pp. 95-128.

Keehn, J. D., \& Colotla, V. A. Schedule-induced drinking as a function of interpellet interval. Psychonomic Science, 1971, 23, 69-71.

(Received for publication September 18, 1975.) 